\title{
PENGALAMAN TRANSMIGRASI DI INDONESIA \\ (Studi di Desa Olak-Olak, Kecamatan Kubu, Kabupaten Kubu Raya)
}

\author{
Andang Firmansyah \\ Pendidikan Sejarah FKIP Universitas Tanjungpura, \\ Email: andang.firmansyah@gmail.com \\ Superman \\ Pendidikan Sejarah IKIP PGRI Pontianak, \\ Email: namakusuperman@gmail.com \\ Galuh Bayuardi \\ Pendidikan Geografi IKIP PGRI Pontianak, \\ Email: zegavon@gmail.com
}

\begin{abstract}
Abstrak
Penelitian ini bertujuan untuk memaparkan mengenai transmigrasi di desa olak-olak kecamatan Kubu Kabupaten Kubu Raya. Metode penelitian menggunakan metode historis dengan langkah-langkah heuristic, kritik sumber, interpretasi dan penulisan sejarah. Hasil penelitian menunjukan bahwa Provinsi Kalimantan Barat khususnya Desa Olak-Olak merupakan salah satu tempat tujuan transmigrasi di Indonesia. Kelompok transmigrasi yang pertama datang pada tahun 1958 sampai dengan tahun 1959. Rata-rata transmigran ini berasal dari daerah Jawa Tengah dan sekitarnya. Oleh sebab itu budaya Jawa masih sangat kental ditemui di Desa Olak-Olak ini, akan tetapi mulai memudar pada generasi-generasi selanjutnya. Keadaan Desa Olak-Olak ini sampai sekarang masih dikatakan belum berkembang karena terhambat banyak faktor salah satunya adalah transportasi.
\end{abstract}

Kata Kunci : Kepadatan Penduduk, Transmigrasi, Desa Olak-Olak

\begin{abstract}
This study aims to explain about transmigration in the village of Olak-olak, Kubu Subdistrict, Kubu Raya District. The research method uses historical methods with steps heuristic, source criticism, interpretation and writing of history. The results showed that the Province of West Kalimantan, especially the Village of Olak-Olak, was one of the destinations for transmigration in Indonesia. The first transmigration group arrived in 1958 until 1959. On average, these transmigrants came from the regions of Central Java and beyond. Therefore, Javanese culture is still very thick in this Olak-Olak Village, but begins to fade in later generations. The situation of Olak-Olak Village is still said to have not developed because it is hampered by many factors, one of which is transportation.
\end{abstract}

Keywords: Population Density, Transmigration, Olak-Olak Village

\section{PENDAHULUAN}

Kepadatan penduduk di Pulau Jawa dan Madura menurut data dari Badan Pusat Statistik (BPS) pada tahun 2010 adalah 136.610.590 jiwa. Hal tersebut berbanding jauh dengan Pulau Kalimantan yang hanya 13.787.831 jiwa.
Ketimpangan jumlah penduduk antara Pulau Jawa dan Madura dengan pulau lainnya sangat besar. Oleh sebab itu pemerataan penduduk terus menerus digalakkan salah satunya dengan program transmigrasi. Jauh sebelum negara Indonesia merdeka, program 
perpindahan penduduk ini sudah dilaksanakan, tentu saja dengan tujuan yang menguntungkan kolonialisme. Program perpindahan penduduk di Masa Kolonial gencar dilakukan pada saat dibukanya perkebunan. Kolonial Belanda menginginkan tenaga kerja yang murah serta mudah. Program ini kemudian berlanjut pada masa politik etis, walaupun tujuan awalnya untuk pemerataan jumlah penduduk akan tetapi banyak terjadi penyelewengan. Kemudian setelah Indonesia merdeka, masalah kepadatan penduduk di Pulau Jawa dan Madura masih menjadi perhatian serius pemerintah. Oleh sebab itu Pemerintahan Soekarno mencanang program transmigrasi pada tahun 1950 yang diselenggarakan oleh Dinas Transmigrasi (Jawatan Transmigrasi). Provinsi Kalimantan Barat khususnya Desa Olak-Olak merupakan salah satu tempat tujuan transmigrasi di Indonesia. Kelompok transmigrasi yang pertama datang pada tahun 1958 sampai dengan tahun 1959. Rata-rata transmigran ini berasal dari daerah Jawa Tengah dan sekitarnya. Oleh sebab itu budaya Jawa masih sangat kental ditemui di Desa Olak-Olak ini, akan tetapi mulai memudar pada generasi-generasi selanjutnya. Keadaan Desa Olak-Olak ini sampai sekarang masih dikatakan belum berkembang karena terhambat banyak faktor salah satunya adalah transportasi. METODE PENELITIAN
Kajian ini menggunakan metode sejarah dengan beberapa langkah dalam pelaksanaanya. Heuristik sebagai langkah pertama dari penelitian sejarah. Heuristic adalah pengumpulan sumbersumber terkait dengan penelitian, dalam hal ini data-data diperoleh dari berbagai literatur, artikel, majalah, Koran dan hasil wawancara. Kemudian dilakukan kritik atas data-data yang telah didapat untuk kemudian ditafsirkan sebagaimana fakta-fakta yang telah diperoleh. Langkah terakhir yakni dengan melakukan penulisan sejarah.

\section{PEMBAHASAN}

\section{Sejarah Migrasi di Indonesia}

\section{Gelombang Pertama (1905 - 1931)}

Migrasi penduduk di Indonesia dimulai ketika masa Pemerintahan Kolonial Belanda. Gelombang pertama migrasi dilaksanakan antara rentan waktu 1905-1931. Pada waktu itu Pemerintah Kolonial Belanda memerintahkan Asisten Residen, H.G. Heijting, untuk menganalisa kemungkinan perpindahan penduduk Karesidenan Kedu keluar Pulau Jawa. Heijting menyarankan agar membangun kelompok inti yang terdiri dari 500 Kepala Keluarga. Kemudian Pemerintah Kolonial Belanda memberikan jaminan hidup selama setahun. Kemudian satu keluarga diberikan bantuan untuk mendatangkan sanak saudara ke daerah transmigrasi, maka lama kelamaan akan 
memicu transmigrasi spontan (Levang, 2003, hal. 9).

Rencana pemindahan 500 Kepala Keluarga tersebut terlalu muluk, sehingga Heijting menyusutkan jumlah kepala keluarga menjadi 155 saja. Kepala keluarga tersebut berasal dari Karesidenan Kedu, Jawa Tengah yang dikirim ke Gedong Tataan (Lampung). Koloni pertama tersebut berhasil membangun desa yang kemudian diberi nama Bagelen. Kemudian empat desa lainnya dibangun pada tahun 1906 dan 1911. Setiap kepala keluarga mendapatkan 70 are sawah dan 30 are pekarangan, biaya transportasi ke lokasi, bahan bangunan, peralatan, dan jaminan hidup selama dua tahun (Levang, 2003, hal. 10).

Setelah melalui perhitungan, ternyata biaya yang dikeluarkan untuk penempatan koloni tersebut sangat mahal hingga akhirnya biaya tersebut harus ditanggung oleh koloni perintis. Untuk mengatasi tersebut kemudian didirikan sebuah bank (Lampongsche Volksbank) dengan tugas menyediakan kredit untuk para koloni. Koloni Wonosobo (dekat Kota Agung) didirikan dengan pola tersebut pada tahun 1921. Dua percobaan lainnya yaitu di Pulau Sulawesi dan Pulau Kalimantan gagal total. Hal ini dikarenakan manajemen yang buruk, terlalu mudah memberikan bantuan kepada pendatang, dan koloni sulit melunasi hutang hingga akhirnya bank tersebut bangkrut. Walaupun bank tersebut bangkrut akan tetapi arus migrasi ke Lampung terus berjalan (Levang, 2003, hal. 10).

\section{Gelombang Kedua (1931-1941)}

Program transmigrasi kembali digalakkan oleh Pemerintah Kolonial Belanda. Krisis yang melanda sektor perkebunan berdampak kepada penghentian tenaga kerjanya. Pada tahun 1905-1941 Pemerintah Belanda telah memindahkan sekitar 200.000 jiwa dari Jawa keluar Pulau Jawa. Akan tetapi pada waktu kurun yang sama lonjakan penduduk Pulau Jawa sangat besar yaitu dari 30.000.000 jiwa menjadi 45.000.000 jiwa. Ketika Indonesia telah merdeka program tersebut kembali dijalankan walaupun banyak mengkritik kesalahankesalahan pada masa penjajahan. Akan tetapi untuk menghilangkan konotasi negatif, Pemerintah Indonesia di era Presiden Soekarno mengganti penamaan kolonisasi menjadi transmigrasi. Aturan yang dibuat untuk para transmigran pun juga beberapa masih mengadopsi aturanaturan dari Pemerintah Kolonial Belanda. Diantaranya aturan tersebut adalah kelompok perintis harus menanggung biaya bagi kelompok transmigrasi pada tahap selanjutnya.

\section{Kendala Transmigrasi di Indonesia}

Salah satu kendala dari program transmigrasi adalah falsafah yang dianut oleh Orang Jawa sendiri. Menurut 
pendapat Geertz, Orang Jawa cenderung bertahan tinggal di tempat asal walaupun dalam keadaan yang memprihatinkan. Geertz menyebutnya sebagai shared poverty (kemiskinan yang dibagi rata; memiskinkan bersama). Masyarakat desa tidak didasarkan pada yang punya dan tidak punya akan tetapi lebih kepada cukupan dan kekurangan (Geertz, 1983, hal. 102). Oleh sebab itu, jika lahan persawahan diibaratkan kue, maka kue tersebut akan terus menerus dibagi tergantung dari jumlah anak yang dimiliki. Anggapan bahwa banyak anak, banyak rejeki masih menyelimuti pikiran Orang Jawa pada waktu itu. Maka akibatnya petani di Pulau Jawa lama kelamaan tidak akan memiliki lahan persawahan lagi.

Selain itu juga anggapan tentang daerah Luar Pulau Jawa masih sangat asing bagi masyarakat Jawa sendiri. Disamping itu juga mereka lebih memilih untuk tetap bersama walaupun lahan sudah menyempit. Menurut ramalan Malthus mengatakan bahwa sawah di Pulau Jawa tidak mungkin akan diperluas lagi. MenaMbah jumlah petani sama saja dengan menaMbah pembagian sawah yang ada di Pulau Jawa. Usaha meningkatkan hasil produksi pertanian di Pulau Jawa adalah dengan intensifikasi yaitu dengan memaksimalkan pencangkulan tanah dan pemupukan (Levang, 2003, hal. 52).

\section{Transmigrasi Orang Jawa di Desa Olak- Olak}

Migrasi pertama masyarakat Jawa di Desa Olak-Olak berlangsung antara tahun 1958-1959. Kedatangan transmigran pertama kali di Desa OlakOlak berjumlah 17 Kepala Keluarga dengan jumlah rombongan 66 jiwa yaitu sebagai berikut.

Tabel 1. Kelompok Transmigrasi Gelombang I

\begin{tabular}{l|l|c}
\hline No. & \multicolumn{1}{|c|}{ Nama } & Jumlah Jiwa \\
\hline 1 & Suradi & 4 \\
\hline 2 & Radan & 6 \\
\hline 3 & Muljo Diharjo & 3 \\
\hline 4 & Niti Semito & 4 \\
\hline 5 & Tikat & 2 \\
\hline 6 & Kandar & 8 \\
\hline 7 & Miharjo Kasdi & 4 \\
\hline 8 & Somo Tijono & 4 \\
\hline 9 & Kasmiran & 2 \\
\hline 10 & Noto Suharno & 3 \\
\hline 11 & Pawiro Selamet & 4 \\
\hline 12 & Muin & 4 \\
\hline 13 & Jumadi & 2 \\
\hline 14 & Rebi & 3 \\
\hline 15 & Dul Rasit & 4 \\
\hline 16 & Rasiman & 3 \\
\hline 17 & Karto Saribun & \\
\hline
\end{tabular}

(Dokumen Pribadi Bapak Suradi) 
$\begin{array}{ccc} & \text { Proses transmigrasi dari Pulau } \\ \text { Jawa menuju Pulau Kalimantan }\end{array}$ menempuh perjalanan yang panjang dan membutuhkan waktu berbulan-bulan. Hal ini bukan saja karena kendaraan saat itu masih begitu sederhana, dari proses pendaftaran, keberangkatan, dan beberapa kali transit atau ditampung di rumah-rumah singgah beberapa kali. Persinggahan tersebut para transmigran tinggal dalam waktu beberapa minggu sampai beberapa bulan.

Persinggahan pertama berada di dinas transmigrasi di Jakarta. Di Jakarta mereka bertemu dengan kelompokkelompok transmigran yang berangkat dari berbagai daerah dari Pulau Bali, Nusa Tenggara Barat, Jawa Timur, Jawa Tengah dan juga Jawa Barat. Kelompokkelompok tersebut dari Jakarta nantinya akan diberangkatkan ke berbagai daerah di Pulau Sumatera, dan Pulau Kalimantan.

Kelompok per kelompok diberangkatkan dengan menggunakan kapal laut, setiap kelompok menanti untuk diberangkatkan, dengan berbekalkan harapan baru, di tempat yang baru. Berikutnya tiba akhirnya pemberangkatan kelompok transmigran dengan tujuan Kalimantan Barat. Salah satu kelompok adalah yang bertujuan ke Kecamatan Kubu, Kabupaten Kubu Raya, Kalimantan Barat. ransmigran dengan tujuan desa Olak-olak Kubu datang secara bertahap menjadi 4 gelombang selama kurun waktu tahun 1958-1959.

Kondisi daerah tujuan saat itu masih berupa hutan, hanya beberapa lahan hutan yang sudah dibabat pohon dan semak belukar untuk masing-masing rumah, dengan kayu-kayunya masih belum dibersihkan. Rumah untuk masingmasing keluarga belum ada, sehingga mereka selama beberapa bulan bahkan sampai dengan dua tahun masih tinggal di rumah penampungan sementara yang berupa bedeng atau barak yang terbuat dengan atap daun dinding sebagian kayu dan anyaman daun. Keadaan rumah ketika masing-masing kepala keluarga dibangun, rumah mereka masing-masing dengan dinding dua papan dan dinding daun, begitu pula dengan atapnya. Rumah-rumah transmigran satu persatu dibangun secara gotong-royong, dengan ukuran $4 \times 6 \mathrm{~m}^{2}$, sekitar dua tahun, akhirnya rumah dari 17 Kepala keluarga tersebut berdiri, dengan kondisi yang sangat sederhana. Masing-masing kepala keluarga dibekali dengan 1 Kapak, 1 Parang, 1 cangkul, dan satu Linggis, 1 Wajan kecil untuk goreng teri, dan 1 ketel besi (kapasitas $1 \mathrm{Kg}$ Beras), sementara selama 4 tahun mendapatkankan jatah bantuan hidup setiap kepala keluarga mendapatkan beras 7 Kilogram beras, 1 liter minyak goreng, dan 1 Liter minyak tanah. Saat itu mereka memasak dengan menggunakan bahan bakar kayu. 
Selama dua belas tahun menurut Pak Suradi, lahan untuk menanam tanaman pangan belum ada, karena semua masih hutan, selama itu mereka masih mengandalkan kiriman bantuan dari pemerintah. Pernah terjadi kiriman bantuan tersebut terhenti selama delapan bulan, dan dalam waktu terhentinya kiriman tersebut, mereka bertahan hidup dengan mengkonsumsi talas (keladi), dan beberapa ketua kelompok meminta bantuan dari desa tetangga dan mendapatkan bantuan berupa ubi kayu/singkong kering/ gaplek.

Kisah tersebut masih diceritakan oleh Pak Suradi, beliau adalah transmigran angkatan pertama sebagai ketua kelompok dari Jawa Tengah, sebanyak 17 kepala keluarga yang terdiri dari 66 orang. Pak Suradi berasal dari Ambarawa Jawa Tengah sekitar danau rawa pening. Pak Suradi kembali menceritakan bahwa panen dari tanaman warga desa Olak-olak Kubu yang pertama adalah panen ubi rambat, sebanyak 4 ton pada tahun 1966. Ubi rambat tersebut tidak dapat dipasarkan ke mana pun saat itu. Ubi rambat tersebut akhirnya di dibawa oleh Pak Suradi bersama dua orang dengan menggunakan tongkang dayung untuk membawa 4 ton ubi tersebut untuk dijual. Saat itu beliaupun belum tahu akan dijual ke mana. Akhirnya beliau berangkat dengan tongkang dayungnya ke arah Tanjung
Bunga, dan di tempat tersebutpun ubi masih banyak, dan sedikit pembeli, beliau mendapatkan informasi, biasa di daerah hulu pasti banyak orang yan membeli. Tanpa mengetahui posisi arah dan tempat Pak Suradi bersama kawannya terus mendayung hingga Teluk Pakedai, Sungai Pinyuh, kembali ke Sungai Kakap, menyusur Parit Gaduh, Sungai Jawi, dan sungai Ambawang, hanya berdasarkan petunjuk dari yang ditemui orang-orang. Setiap malam tiba, pak Suradi tidur dalam tongkangnya, di beberapa tempat yang ia singgahi. Di Sungai Ambawang, Pak Suradi hendak melanjutkan perjalanan menghabiskan persediaan ubi ke arah hulu, namun ditengah perjalanan dihentikan oleh beberapa orang Dayak, di sekitar desa Korek Lingga, mereka menyarankan untuk balik arah karena di hulu sedang terjadi perselisihan antara China dan Dayak, sementara keadaan di hulu tidak aman, selain karena hari menjelang malam, akhirnya pak Suradi memutuskan untuk singgah dan bermalam di tongkangnya yang ditambatkan di depan rumah kepala desa. Hal itu terjadi setelah menempuh perjalanan air selama 15 hari.

Pak Suradi mengatakan, “ nek ora niat nguripi keluarga, ra mungkin ndayung nganti tekan kono-kono" (jika bukan karena niat untuk menghidupi keluarga, tidak mungki mengayuh dayung sampai sejahuh itu). Setelah perselisihan 
antara etnis Dayak dan Etnis Cina mereda, Pak Suradi masih melakukan hal tersebut empat kali, bersama dengan Almarhum Pak Marto dan Pake Sastro asal Klaten.

Panen pertama setelah 6 tahun berada di desa Olak-olak hanyalah palawija, mereka belum bisa menanam padi. Pak Suradi mengatakan bahwa mereka mulai menanam padi pada era pemerintahan Suharto. Jenis padi yang mereka tanam adalah padi dengan usia tanam 7 bulan, sebagaimana yang ditanam orang-orang melayu.

Penanaman padi tersebut juga dimungkinkan karena pada era awal Suharto, parit-parit dibuat lebih besar dengan menggunakan alat berat, sehingga selain drainase di desa Olakolak Kubu menjadi lancar, dan jika air sungai pasang rumah tidak terendam, air dari parit-parit tersebut dapat digunakan untuk mengairi lahan sehingga memungkinkan untuk menanam padi.

\section{Strategi Bertahan Ketika Pertanian} Belum dapat dijadikan Sandaran

Sejak kedatangan awal para transmigran, pertanian belum dapat dilakukan tanaman palawija sekalipun baru dapat menghasilkan pada tahun ke 6-10 sejak kedatangan mereka. Air yang terlalu asam membuat tanamantanaman pertanian sulit hidup dan tumbuh, selain air lebih banyak menggenang dan sulit untuk dialirkan.
Banyak tanaman yang bias hidup di Jawa tetapi tidak bisa hidup. Mbah Suradi mengatakan,

“ Jenis padi lahan kering... di sini, cabe kena air nggak bisa tumbuh. Saya bawa buncis, kapri dari jawa, kena air mati saat berbunga...

Pertanian dengan keanekaragaman jenis tanaman baru mulai sejak tahun 80-an. Ketika masa Orde Baru bersamaan dengan program swasembada beras, pada masa itu banyak mulai dicetak sawah. Hal yang kemudian menjadi pertanyaan di sini adalah bagaimana para transmigran bertahan.

Pertanyaan tersebut terjawab oleh salah satu nara sumber yang bernama Mbah Nyoto ketua kelompok transmigran yang berasal dari Jawa Timur. Kelompoknya terdiri dari 25 kepala keluarga, namun yang sampai hari ini masih bertahan tinggal di Olak-olah hanya keluarga beliau, yang lain sudah pindah ke Rasau dan Sungai Durian. Beliau menceritakanan tentang bagaimana para transmigran bertahan untuk tetap di Olak-olak. Menurut beliau, Mbah Nyoto dan kelompoknya bertahan dengan berdagang, menjual daun simpur, mencari rotan, bekerja di saw mill, perusahaan kayu, menjadi tukang batu (buruh bangunan) dan sebagian kecil ikut menjadi nelayan. Mengingat saat itu Desa Olak-olak masih hutan penuh kayu, dengan demikian menebang 
pepohonan sekaligus membersihkan dan membuat jalan-jalan setapak. Kurang lebih tahun 70 di sana mulai banyak perusahaan kayu yang mempekerjakan masyarakat transmigran untuk mengambil kayu.

Beberapa pengalaman berikut merupakan beberapa pengalaman dari Mbah Suradi dan Mbah Nyoto dalam mempertahankan kehidupannya. Mbah Suradi mengatakan bahwa ia bertanggungjawab juga pada kelompok transmigran yang diketuainya. Pada suatu saat beliau bertemu dengan seorang yang membutuhkan tenaga buruh bangunan untuk membangun beberapa bangunan fasilitas umum di Kabupaten Bengkayang. Beliau mengajak semua laki-laki yang merupakan anggota kelompoknya, ia mengatakan,

$$
\begin{aligned}
& \text { “... opo wae sing iso digarap yo } \\
& \text { digarap... opo meneh iso ngajak } \\
& \text { kancane kanggo golek rejeki yo } \\
& \text { mangkat bareng... koyo dene } \\
& \text { mbiyen seko jowo budal } \\
& \text { bareng...” }
\end{aligned}
$$

Begitu pula ketika ada pekerjaanpekerjaan baik merupakan proyek pemerintah maupun dari beberapa perusahaan kayu yang saat itu banyak membutuhkan tenaga buruh, seperti misalnya pada saat persiapan lokasi transmigran baru di wilayah lain di desa Air Putih tahun 80an. Baik Mbah Suradi maupun Mbah Nyoto mereka bersama anggota kelompoknya juga sering ikut dalam proyek tersebut. Sebagaimana yang dikatakan Mbah Nyoto,

“...desa Air Putih sekarang maju sekali... dulu saya ikut membuka hutan, bikin jalan... nggali-nggali parit.. eh kemaren saya lewat di sana sudah jauh lebih maju, jalan sudah bagus, banyak yang punya mobil... Olak-olak ini yang lebih dulu ada kok malah ketinggalan jauh pembangunannya..."

Salah satu usaha untuk menaMbah pendapatan rumah tangga, istri Mbah Suradi pernah cukup lama membuat tahu. Namun sekarang karena istri Mbah Suradi sudah sakit-sakitan karena pernah terjatuh, maka usaha pembuatan tahu tersebut berhenti. Istri Mbah Suradi mengatakan,

“....dulu saya itu pembuat tahu, sampai ke sungai rasau... coba aja kalau di sana tanya Mbah Marisah... semua orang kenal. Usaha tahu simbah ini perama dibuat sebelum ada listrik... bikin tahu kurang lebih selama 35 tahun..."

Istri Mbah Suradi bernama Mbah Marisah, usaha tahu yang dikelolanya sendiri, dan dijual sendiri, dan dulu jangkauan pasarnya sampai ke Rasau. Usaha tersebut berjalan cukup lama, dan hal ini sangat membantu mendukung keadaan ekonomi keluarga Mbah Suradi.

Mbah Suradi ternyata pernah juga menjadi nelayan pada tahun, beliau ikut nelayan-nelayan lokal yang merupakan pendahulu dan pemilik perahu. Mbah Suradi berhenti menjadi nelayan karena tidak diperbolehkan oleh istrinya, 
setelah pernah mengalami kecelakaan. Perahu yang digunakan terbalik tergulung ombak. Beliau terapung-apung di laut lepas selama tiga hari, 6 dari 7 orang di perahu tersebut hilang dan tidak pernah ditemukan. Di hari ke tiga Mbah Suradi ditemukan dan diselamatkan oleh Nelayan dari Padang Tikar, dan sempat dirawat penolongnya selama tiga hari dan kemudian diantar pulang. Laporan dari kepolisian yang menyatakan Mbah Suradi hilang di laut, baru datang setelah Mbah Suradi di rumah.

“... dadi nelayan yo ora ming neng pinggir, tekan laut adoh tengah kono... bar kui ro Mbahe (istri Mbah Suradi) ora oleh nglaut meneh... sakwene bar prau ne keno ombak... kancane simbah yo ilang kabeh wong pitu , ming Mbahe dewe sing tekan ngomah... telung ndino cekelan kayu...kabeh pisah keno ombak... wis cekelan kayu papan... lha ombake gedhe nggulung seko mburi prau... ono sik nulungi... Mbahe wis lemes... surat seko pulisi teko Mbahe wis neng omah"

Kemudian, salah satu kisah yang berkaitan dengan cara bertahan dengan belajar dengan apa saja yang ada dan tersedia untuk menghasilkan sesuatu diceritakan oleh Mbah Nyoto tentang usaha membuat papan. Hal ini dimulai saat terjadi keterlambatan pengiriman jatah hidup dari pemerintah untuk para transmigran. Mbah Nyoto dan beberapa kepala rumah tangga kelompoknya kurang lebih sepuluh orang mendatangi kantor Bumi Raya (pengelola program transmigrasi) di Rasau. Mereka menginginkan untuk mengambil jatah beras mereka yang terlambat. Mbah Nyoto dan teman-temannya bertekat tidak akan pulang kalau belum membawa beras untuk dibawa pulang. Mbah Nyoto menceritakan,

“... Mbah ki sik paling canggih... beras ora entuk... saya melihat ada gergaji (gerjaji besar yang merupakan alat pada sawmill manual)...gergaji itu minta karena beras memang nggak ada... Cuma ada gergaji yang bisa dibawa pulang... sejak itu saya belajar pelan-pelan bikin papan... itu papan pertama kali buatan olakolak..."

Mbah Nyoto tidak serta-merta dapat langsung menggunakan gerjaji tersebut untuk membuat papan dari kayu yang saat itu memang masih banyak di sekitar Olak-olak. Butuh waktu yang cukup lama untuk belajar menggunakannya. Namun karena ketekunan beliau di sela kegiatan mencari nafkah lainnya, dibantu beberapa tetangga Mbah Nyoto akhirnya dapat membuat papan.

\section{Sederhana dan Ketekunan}

Hidup di tempat ataupun lingkungan yang baru dan merintis kehidupan baru bagi transmigran merupakan hal yang sangat berat. Untuk menjalaninya benar-benar dari awal, mulai dari membuka hutan, membangun rumah, dan pada awalnya hanya 
bersandar pada jatah hidup yang minim dari pemerintah saat itu.

Ketekunan menjadi kunci dari kemampuan dan kemauan untuk tetap bertahan tinggal di Olak-olak. Baik Mbah Nyoto maupun Mbah Suradi merupakan orang yang tekun dan mau mengerjakan apapun. Prinsip hidupnya yang sederhana dan tidak mengeluh ataupun menyerah pada keadaan. Sebagaimana ungkapan Mbah Suradi,

“ anggere ana beras, garam ro micin (vetsin, atau penyedap rasa), wis cukup... mudun parit kari nggowo serok wis entu iwak urang, lalapan nggo janganan metiki neng pekarangan... cukup"

Mbah Nyoto melakukan apapun mulai dari menjual daun simpur membuat papan, memelihara ayam kampung, dan apapun yang dapat dikerjakan, bahkan beliau juga termasuk sesepuh seniman dari kelompok kuda lumping Gagak Rimang. Beliau mengatakan,

“ mbuh kenapa... pokoke mesti uthik... ono wae sing digawe, ono sik nandur-nandur, ngingu pitik, sok-sok yo isih neng alas, ono tanduran sayuran, ro pari sithik, nek ono acara kuda lumping main, tekan ngendi-endi siMbah yo diajak nunggoni... yo entuk sangu"

Ketekunan semacam ini yang membuat mereka merasa memiliki kesibukan hingga usia tua mereka, sementara anak, cucu, dan cicit, bahkan canggah (istilah untuk anak dari cicit pada masyarakat Jawa) sudah banyak yang tinggal di luar Olak-olak. Seperti Mbah Suradi, anak cucu mereka sudah menyebar, hingga Kabupaten Ketapang, bahkan ada yang kembali dan tinggal di Jawa. Begitu juga anak cucu Mbah Nyoto, diceritakan ada juga yang sudah meninggal.

\section{KESIMPULAN}

Pemerintah melakukan intervensi pemerintah terhadap permasalahan dan pengelolaan kependudukan, salah satunya adalah migrasi. Di Indonesia hal ini telah dilakukan sejak pemerintah kolonial sampai sekarang. Salah satunya adalah program transmigrasi yang dilaksanakan pada masa pemerintahan Orde Lama, pada masa pemerintahan Presiden Soekarno. Tujuan program pemerintah di setiap periode bervariasi seperti program pemerintah di daerah lain. Pada periode Orde Lama antara lain adalah mempercepat pendistribusian populasi, distribusi kesuburan, dan istilah transmigrasi pada dasarnya adalah pergerakan semangat dari satu tubuh ke tubuh yang lain, sehingga bisa diartikan untuk mempercepat pembentukan integrasi. Negara Kesatuan Republik Indonesia sebagai identitas kebudayaan bangsa Indonesia.

Kedatangan Transmigran dari Jawa ke Olak-Olak pertgama kali pada tahun 1958. Kehidupan awal transmigran di Desa Olak-Olak cukup 
memprihatinkan. Mereka harus menghadaapi berbagai kendala baik berupa permasalahan berupa keterlambatan administrasi jatah perbulan maupun kondisi pemukiman yang masih berupa hutan sehingga harus bekerja ekstra untuk membangun pemukiman yang layak. Kondisi tanah hutan yang belum bisa ditanami padi juga merupakan kendala tersendiri. Beruntungnya para transmigran gelombang pertama adalah orang-orang yang tangguh serta teguh pada pendirian sehingga mereka bahkan hingga sekarang masih tetap betah berada di Olak-Olak.

Berbeda dengan transmigran generasi pertama, banyak transmigran yang datang kemudian tidak betah lalu pindah. Anak-anak dari para transmigran pun banyak yang pergi dari Olak-Olak demi mencari penghidupan yang layak walaupun kehidupan transmigran pada masa Soeharto relatif lebih baik dari sebelumnya. Pada masa Soeharto segala macam infrastruktur juga telah dibangun di Olak-Olak. Lahan-lahan pertanian sudah bisa digarap secara optimal karena telah dibangun saluran-saluran air.

Keputusan untuk mengikuti program dan tinggal di tempat tujuan yang dipilih oleh masyarakat Jawa didasarkan pada bagaimana pandangan dunia yang bergeser, ungkapan, "mangan ora mangan kumpul" tidak lagi dipelihara, karena jika "kumpul" dan "ora mangan" akan berpotensi tidak mampu menjaga kondisi perselisihan "harmonis" atau potensial antara keluarga besar. Melawan perubahan konsep pandangan dunia, dalam hal rasa, kepercayaan, dan sistem nilai, yang dapat dilihat sebagai strategi adaptasi terhadap tempat tinggal mereka, mereka tidak hanya bermigrasi secara fisik, namun juga memigrasikan sudut pandang pada beberapa bagian dari pandangan dunia mereka. Perasaan, keyakinan, dan sistem nilai mereka beradaptasi dengan lingkungan sekitar mereka.

\section{DAFTAR PUSTAKA}

Geertz, C. (1983). Agriculture Involution. (S. Supomo, Trans.) Jakarta: Bhratara Karya Aksara.

Geertz, C. (1973). Interpretation of Culture. New York: Basics Inc Publiser.

Heeren, H.J. (1979). Transmigrasi di Indonesia. Jakarta: Gramedia

Koentjaraningrat, (1994). Kebudayaan Jawa, Jakarta: Balai Pustaka.

Koentjaraningrat, (1990). Pengantar Ilmu Antropologi, Jakarta: Rineka Cipta.

Levang, P. (2003). La terre d'en face - La transmiration en Indonesia. (S. W. Prayoga, Trans.) Jakarta: Gramedia.

Mantra, I. B. (1985). Pengantar Studi Demografi. Yogyakarta: Nurcahaya.

Neni Puji, laporan Penelitian Balai Kajian Jarahnitra Pontianak. (2001). "Migrasi Orang-Orang Kebumen di Sumur Bor, Kecamatan Pontianak Barat Kota Pontianak", Pontianak: Balai Kajian Jarahnitra. 
Pengalaman Transmigrasi di Indonesia..., Andang Firmansyah, dkk, 379- 390 